\title{
Aging In Vitro and D-Glucose Uptake Kinetics of Diploid Human Fibroblasts
}

\author{
T. CREMER, K. WERDAN, A.F.G. STEVENSON, K. LEHNER, AND O. \\ MESSERSCHMIDT \\ Institut für Anthropologie und Humangenetik, D-6900 Heidelberg, (T.C.), \\ Laboratorium für experimentelle Radiologie, D-8042 Neuherberg, (K.L., O.M.), \\ Medizinische Klinik I der Universität München, Klinikum Großhadern, D-8000 \\ München 70, (K.W.), and Institut für Anatomie der Universität Regensburg, \\ D-8400 Regensburg, (A.F.G.S.)
}

\begin{abstract}
By use of a rapid technique, initial rates of D-glucose transport were obtained during the lifespan in vitro of a commercially available strain of human embryo lung fibroblasts (Flow 2000). The apparent $\mathrm{Km}$ of the D-glucose carrier did not change during senescence in vitro: $\overline{\bar{x}}=1.8 \mathrm{mM}$ (range $1.3-2.3$ ) in phase II, $\overline{\mathbf{x}}=1.8 \mathrm{mM}$ (range $1.5-2.2$ ) in phase III. Transport rates remained constant in stationary phase II cultures, which had completed between $30 \%$ and $80 \%$ of their replicative lifespan. A wide variation, however, was observed in terminally differentiated cells (phase III), which showed a two- to threefold increase in average cell size and protein content. In some senescent cultures, glucose transport calculated on a per cell basis was also two- to threefold increased, while it was strongly decreased $(-75 \%)$ in others. When calculated per unit of cell water, protein, and surface area, respectively, transport rates in phase III cultures ranged from values established for stationary phase II cultures down to very low values. Detaching cells flushed off from senescent cultures did not show measurable rates of glucose transport into the inulin impermeable cell space. Present evidence argues against the idea that an impairment of $D$-glucose transport might precede loss of replicative potential in aging human fibroblasts. Instead our data indicate that the transport capacity of cell membrane finally decreases during postreplicative senescence in terminally differentiated cells.
\end{abstract}

Loss of reproductive capacity of human fibroblast cultures has been observed in phase III of their replicative lifespan (Hayflick and Moorhead, '61). It has been suggested that a deterioration of cell membrane functions could play an important role in reproductive cell death and finally in cell degeneration (Berumen and Maciera-Coelho, '77; Zs.-Nagy, '79). Formation of additional plasma membrane material should be expected in senescent cells, due to additional surface area necessary to envelop the enlarged cells (Simons, '67; Haslam and Goldstein, '74; Schneider and Fokles, '76) and to plasma membrane turnover (Roberts and Yuan, '75; Kaplan and Moskowitz, '75; Hirschberg, '77). Biosynthesis, degradation, and assembly of membrane components may, however, be altered (Zs.-Nagy, '79). This may influence the number and function of carriers for specific compounds or allow uncontrolled influx and efflux of substances whose transport is otherwise mediated by specific carrier molecules.
As an approach to answering these questions, we investigated the affinity of the glucose carrier for D-glucose, the velocity of the carrier-mediated D-glucose uptake and the proportion of nonmediated diffusion of D-glucose both in phase II cultures and phase III cultures. We expected that any impairment of D-glucose transport would become the more pronounced the longer senescent cells were maintained in the postreplicative state (Martin et al., '75). For this reason we have tried to maintain cultures that had essentially exhausted their replicative lifespan for several weeks before assays were performed. Glucose transport in these cultures was compared with stationary phase II cultures maintained under

\footnotetext{
Received May 7, 1979; accepted July 25, 1980

A preliminary report of this investigation was presented at the spring meeting of the German society for cell biology in 1979 (Cremer et al., '79).

Address reprint requests to $\mathrm{T}$. Cremer.
} 
a routine subculturing regimen. The initial transport rates of the glucose carrier were measured using silicone layer filtering centrifugation (Klingenberg and Pfaff, '67; Heldt, '80). Briefly, suspended cells were incubated with radioactive compounds for a number of seconds and subsequently separated from the incubation medium by rapid filtration through silicone oil. This method has been found (1) to be rapid enough to allow use of D-glucose instead of resort to analogues, and (2) to cause no change in $\mathrm{Km}$ and Vmax of the carrier-mediated glucose transport during suspension of human fibroblasts in $0.2 \%$ trypsin over a limited period of time (Werdan et al., ' 80 ).

\section{EXPERIMENTAL PROCEDURES}

\section{Cell strain and culture conditions}

A strain of commercially available human embryo lung fibroblasts (HELF), which was derived from lung tissue of a 14- to 15-week-old male Negro fetus, was obtained from Flow Laboratories at population doubling level 18 (Flow 2000, code 0-13200). Q-banding revealed a normal male karyotype (courtesy of D. Hager and U. Müller, Institute of Anthropology and Human Genetics, University of Heidelberg). Culture medium was Eagle's MEM with Earle's salts supplemented with $12 \%$ FCS, non-essential amino acids, penicillin (100 $\mathrm{U} / \mathrm{ml})$, streptomycin $(100 \mu \mathrm{g} / \mathrm{ml})$ and NaHCO3 $(2.2 \mathrm{gm} / 1)$. Medium was freshly prepared and adjusted to $\mathrm{pH} 7.4$ before use. Cultures were incubated in a humidified atmosphere at $37^{\circ} \mathrm{C}$ with $5 \% \mathrm{CO}_{2}$ and $95 \%$ air. Culture medium $(0.3$ $\mathrm{ml} / \mathrm{cm}^{2}$ of growth area) was replaced by fresh medium twice weekly in all phase II and phase III cultures. Periodic tests of phase II and phase III cultures for mycoplasma contamination using the method of double labeling with ${ }^{3} \mathrm{H}$ uracil and ${ }^{14} \mathrm{C}$-uridine gave negative results (Schneider and Stanbridge, '75). Serial subcultivation was started from a common frozen stock of cells. Subcultivation of confluent cultures was performed as described by Hayflick ('65). $8 \times 10^{3}$ cells were plated per $\mathrm{cm}^{2}$ growth area in phase II. When cell growth slowed down in late passage cultures, the time interval between subcultures was increased from 1 to 3 weeks, and subcultures were established at a 1:2 split ratio. Cultures were routinely grown in plastic vessels with $75 \mathrm{~cm}^{2}$ growth area (Falcon). In order to obtain enough cell material for biochemical purposes, vessels with $174 \mathrm{~cm}^{2}$ growth area (Nunc) were used. In several series the replicative capacity of the cultures was exhausted after 68-76 cumulative population doublings (CPD) (Smith and Whitney, '80). The number of CPD allowed us to calculate retrospectively the percentage of completed reproductive lifespan of individual cultures in each series.

\section{Labeling indices}

At each subcultivation, cultures were labeled with ${ }^{3} \mathrm{H}$-thymidine $(0.1 \mu \mathrm{Ci} / \mathrm{ml})$ for 3 days and processed for autoradiography thereafter (Cristofalo and Sharf, '73). The percentage of labeled nuclei was only slightly increased by exposure of the cultures to ${ }^{3} \mathrm{H}$-thymidine up to 7 days (Stevenson et al., '77).

\section{Protein determination}

Protein was determined by the method of Lowry et al. (' 51 ), using crystalline bovine serum albumin as a standard.

\section{Preparation of cell suspensions for D-glucose uptake measurements}

If not stated otherwise, cell suspensions from phase II cultures were prepared 7 days after subcultivation, when these cultures had achieved saturation density. Cell suspensions from phase III cultures were obtained following an extended period of 3-10 weeks, with two changes of medium per week after the last subcultivation at a 1:2 split ratio. Growth of senescent cultures was examined twice weekly in an inverted microscope, and cultures were used for D-glucose uptake studies at times when no further increase in cell number could be observed for at least 2 weeks. In one experiment (No. 1) a final subcultivation of senescent cultures was performed at a 1:1 ratio 1 week before assay in order to get rid of degenerating cells. This treatment resulted in a very substantial loss of cells (up to $80 \%$ ), which did not reattach. Final cell densities in senescent cultures varied between 3,300 and 19,600 cells $/ \mathrm{cm}^{2}$, while cell densities of confluent phase II cultures varied between 40,000 and $90,000 \mathrm{cells} / \mathrm{cm}^{2}$ at different passage levels. These low values indicate that senescent cultures had reached the very end of their replicative lifespan. In order to use similar cell numbers for uptake studies in phase II and phase III, additional subcultures were established when cultures approached the end of phase II so that a sufficient number of phase III cultures could be pooled in each experiment. Routinely, all phase III and phase II cultures were provided with fresh medium 24 hours before assay. For enzymatic digestion, $0.2 \%$ trypsin (Serva, 1:250, Cat. No. 33634) was dissolved in a salt solution containing $137 \mathrm{mM}$ 
$\mathrm{NaCL}, 5.4 \mathrm{mM} \mathrm{KCl}, 4.8 \mathrm{mM} \mathrm{NaHC03,20 \textrm {mM }}$ HEPES, $0.1 \mathrm{mM}$ EDTA, and $0.001 \%$ phenol red as $\mathrm{pH}$ indicator; the final $\mathrm{pH}$ was adjusted to 7.4 at $20^{\circ} \mathrm{C}$ (Werdan et al., ' 80 ). Cultures were washed three times with the salt solution before trypsin solution was applied. Phase III cultures were gently shaken for 2 minutes before each wash to remove loosely attached senescent cells and cell debris. Phase contrast observation of these "degenerating cell fractions" showed large senescent cells and small vesicles that may have formed from membranes of degenerating cells. Firmly attached cells and degenerating cell fractions were separately processed for uptake measurements. The time interval between the start of trypsinization and measurement of glucose uptake was $30 \mathrm{~min}$ utes in all experiments. Cell counts were performed under phase contrast in three Neubauer chambers.

\section{Estimation of cell surface area}

Phase contrast micrographs from suspended cells in Neubauer chambers were taken randomly. The area occupied by each of approximately 1,000 cells was determined by planimetry from enlarged negatives. Surface areas of individual cells were estimated by assuming the cells to be smooth spheres. Average volumes per $10^{6}$ cells when estimated under this assumption were in good agreement with volumes obtained by a biochemical method described below. The cell surface area per $10^{6}$ cells was estimated either by integrating the surface area of approximately 1,000 individual cells or by simply taking into account the mean cell space, assuming the cell sample to be uniform in size. Both estimates agreed closely, in spite of the large heterogeneity of cell size in phase III cultures.

\section{Determination of cell space}

A silicone oil filter-centrifugation technique (Klingenberg and Pfaff, '67; Heldt, '80) was adopted for work with human diploid fibroblasts (Werdan et al., '80). Determination of cell space was achieved by measuring the total ${ }^{3} \mathrm{H}$-water space in the sediment and subtracting from it the extracellular space of medium adherent to the sedimented cells. Correction was achieved (1) by measuring the ${ }^{14} \mathrm{C}$-inulin space (Haslam and Goldstein, '74), and (2) by measuring ${ }^{14} \mathrm{C}$-glucose uptake within the linear range and interpolating graphically to time zero. This value indicates the amount of glucose present in the extracellular space and thus allows calculation of this space (Werdan et al.,
'80). The amount of ${ }^{14} \mathrm{C}$-inulin found in the sediment remained constant with increasing incubation time (1-15 min). Procedures 1) and 2) gave identical values for the extracellular space.

\section{Measurement of D-glucose uptake}

Measurement of sugar uptake into suspended human fibroblasts has been described in detail elsewhere (Werdan et al., '80). Briefly, the fibroblasts were equilibrated with ${ }^{3} \mathrm{H}-\mathrm{H}_{2} \mathrm{O}$ in the incubation medium and thereafter incubated with ${ }^{14} \mathrm{C}$-glucose for a number of seconds. Incubation was terminated by centrifugation through silicone oil. Decays per minute of ${ }^{14} \mathrm{C}$ glucose and ${ }^{3} \mathrm{H}-\mathrm{H}_{2} \mathrm{O}$ were determined both in the sediment and in an aliquot of the incubation medium. The amount of the ${ }^{14} \mathrm{C}$-radioactivity determined in the sediment was corrected for the extracellular space as described above and served to calculate D-glucose uptake per $\mu \mathrm{l}$ cell space. All measurements were performed in triplicate. The sensitivity of the method to measure very low transport rates is limited by the accuracy with which the extracellular space in the sediment can be determined after filtering centrifugation.

\section{RESULTS}

\section{In vitro senescence of human diploid embryo} lung fibroblasts (HELF) strain Flow 2000

Figure 1 shows the ${ }^{3} \mathrm{H}-\mathrm{TdR}$ labeling index (Cristofalo and Sharf, '73) as a function of the exhausted replicative lifespan for this strain of fibroblasts. The labeling index decreased only slightly during the course of phase II. Cultures that had completed more than $90 \%$ of their replicative lifespan showed thereafter a sharp drop in the labeling index. A two- to threefold increase of the mean cell volume was found in phase III cultures as compared to stationary phase II cultures (Fig. 2, Table 1). The mean volume obtained from exponentially growing cultures was somewhat smaller $(1.6 \pm 0.2 \mu \mathrm{l} /$ $10^{6}$ cells) than that of confluent phase II cultures $\left(2.6 \pm 0.4 \mu \mathrm{l} / 10^{6}\right.$ cells). Figure 2 shows that the increase in the mean volume of senescent cultures was associated with an increase in the mean protein content (Schneider and Shorr, '75; Schneider and Fokles, '76). The protein content per $\mu \mathrm{l}$ cell water did not change during in vitro senescence in this cell strain: In six phase II cultures that had completed between $60 \%$ and $80 \%$ of their replicative lifespan, we found $0.23 \pm 0.060 \mathrm{mg}$ protein per $\mu \mathrm{l}$ cell water, while $0.21 \pm 0.052 \mathrm{mg}$ protein per $\mu \mathrm{l}$ 


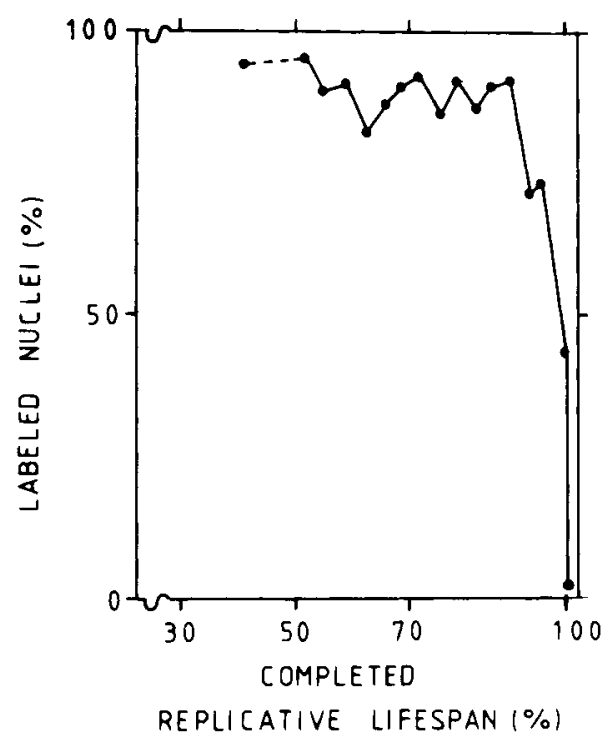

Fig. 1. Subcultures were incubated in the presence of ${ }^{3} \mathrm{H}$-tdR for 72 hours and processed for autoradiography. The percentage of labeled nuclei was determined as a function of completed replicative lifespan of the human embryo lung fibroblast (HELF) strain Flow 2000.

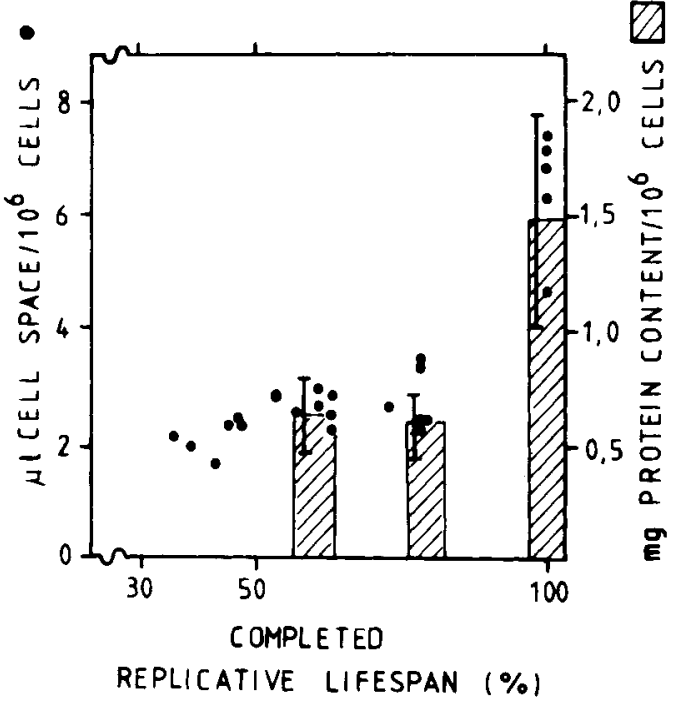

Fig. 2. The cell space and protein content of HELF-strain Flow 2000 are shown as a function of completed replicative lifespan. Each point represents the average cell space of a culture obtained by triplicate measurements with silicone layer filtering centrifugation. Columns represent the protein content measured in three to five cultures; standard errors are indicated. A significant increase of cell space and protein content is observed in phase III cultures.
TABLE 1. Cell space and intial transport rates at $0.1 \mathrm{mM}$ D-glucose in phase II and phase III HELF-cultures

\begin{tabular}{|c|c|c|c|c|}
\hline \multirow[t]{2}{*}{ Exp. No } & \multicolumn{2}{|c|}{$\begin{array}{l}\text { Cell space } \\
\mu \mathrm{l} / 10^{\circ} \text { cells }\end{array}$} & \multicolumn{2}{|c|}{$\begin{array}{c}\text { Transport rate } \\
\text { nmoles } \times 10^{3} / \mu \mathrm{l} \times \min \end{array}$} \\
\hline & phase II & phase III & phase II & phase III \\
\hline 1 & $2.5 \pm 0.15$ & $7.1 \pm 0.22$ & $120 ? 14$ & $73 \pm 6$ \\
\hline 2 & $2.9 \pm 0.16$ & $4.7 \pm 0.13$ & $136 \pm 7$ & $51 \pm 4$ \\
\hline 3 & $2.3 \pm 0.24$ & $6.3 \pm$ & $158 \pm 17$ & $13 \pm 10$ \\
\hline 4 & $2.4 \pm 0.22$ & $6.8 \pm 0.15$ & $101 \pm 13$ & $108 \pm 7$ \\
\hline 5 & $2.4 \pm 0.10$ & $7.3 \pm 0.13$ & $149 \pm 7$ & $58 \pm 7$ \\
\hline & 2.5 & 6. & 133 & 61 \\
\hline range & $2.3-2.9$ & $4.7-7.3$ & $101-158$ & $13-108$ \\
\hline
\end{tabular}

Measurements were performed in triplicate. Average values and standard deviation are indicated in each experiment.

cell water were determined in seven senescent cultures that had been maintained between 1 and 10 weeks after their final subcultivation.

\section{D-glucose uptake of phase II and phase III HELF-cultures}

Five experiments were performed to compare the D-glucose uptake of phase II and phase III cultures at saturation density. For each experiment cell suspensions were prepared from phase II and phase III cultures on the same day and were measured under identical conditions. In vitro aging experiments were carried out in two laboratories from common frozen stock, and senescent cultures were used for uptake measurements after the labeling indices had dropped below $5 \%$ and cultures showed no further proliferation. This indicates that the large majority of cells in these cultures were in a terminally differentiated state (Martin et al., '75). Phase II cultures used for comparison showed labeling indices between $80 \%$ and $95 \%$, and parallel cultures grew vigorously at further subcultivation.

All experiments included controls to check that the uptake of $\mathrm{D}$-glucose was linear within the time range of measurements. At five glucose concentrations in the medium from 0.1-10 $\mathrm{mM}$, uptake was measured for different incubation times ranging from $10-50 \mathrm{sec}$. For the range of D-glucose concentrations used in the present experiments, it was confirmed that linear extrapolation of glucose uptake from $10-20 \mathrm{sec}$ to zero time yielded zero uptake into the inulin-impermeable cell space of phase II and phase III cultures. We suggest, therefore, that D-glucose uptake was linear within the first $20 \mathrm{sec}$ (see also Werdan et al., ' 80 ). The 
extracellular space in the sediment determined by ${ }^{14} \mathrm{C}$-inulin was $27.1 \pm 2.5 \%$ (S.E.M.) of the total water space in phase II and $26.3 \pm 2.2 \%$ in phase III (Haslam and Goldstein, '74). Corresponding values obtained by linear extrapolation of D-glucose to zero time were $25.8 \pm 1.0 \%$ in phase II and $26.7 \pm 2.6 \%$ in phase III. These data argue against an increased leakiness of senescent cell membrane to inulin. It may be noted, however, that cell suspensions from phase III cultures were prepared from firmly attached cells after removal of loosely attached cells and cell debris. Measurements performed with this "degenerating cell fraction" (see Experimental Procedures) revealed that both the ${ }^{14} \mathrm{C}$-inulin space and the ${ }^{14} \mathrm{C}$-glucose space obtained by extrapolation to zero time incubation were considerably increased in comparison with firmly attached senescent cells and phase II cells, and varied between $40 \%$ and $60 \%$ of the total water space in the sediment. This could be due to an increased leakiness of plasma membrane of degenerating cells or an increased adsorption of inulin and glucose to these membranes. Degenerating cell fractions incubated with 0.1 and $1 \mathrm{mM}$ D-glucose for 10 and $20 \mathrm{sec}$ did not show measurable initial rates of uptake into the inulin-impermeable cell space. By the sensitivity of the method applied, we should have detected rates in the range established for suspensions from firmly attached cells described below.

The stereo-specifity of the transport process for D-glucose was demonstrated by the fact that initial rates of uptake of L-glucose were only $2 \%$ of the rates obtained for D-glucose. Transport rates obtained for D-glucose-6-phosphate, D-fructose, D-fructose-6-phosphate, and sucrose were also more than one order of magnitude lower than the rates for D-glucose (Werdan et al., '80). Figure 3 demonstrates typical transport kinetics of phase II cultures and terminal phase III cultures as a function of D-glucose concentration in the medium. S/v versus $S$ plots as shown in Figure 3 were preferred to the widely used Lineweaver-Burk plots. In this way, the participation of a non-saturable component could easily be detected by a deviation from linearity at increasing D-glucose concentrations. A straight linearity of $S / v$ versus $S$ was observed between $0.1 \mathrm{mM}$ and $6 \mathrm{mM} \mathrm{D-glu-}$ cose. Linear regression lines when calculated for this range of concentrations showed correlation coefficients $r$ between 0.995 and 0.999 in all experiments, except for phase III cultures in experiment 3 . In this experiment uptake of senescent cells was too low to be accurately measured by the present method. In the other

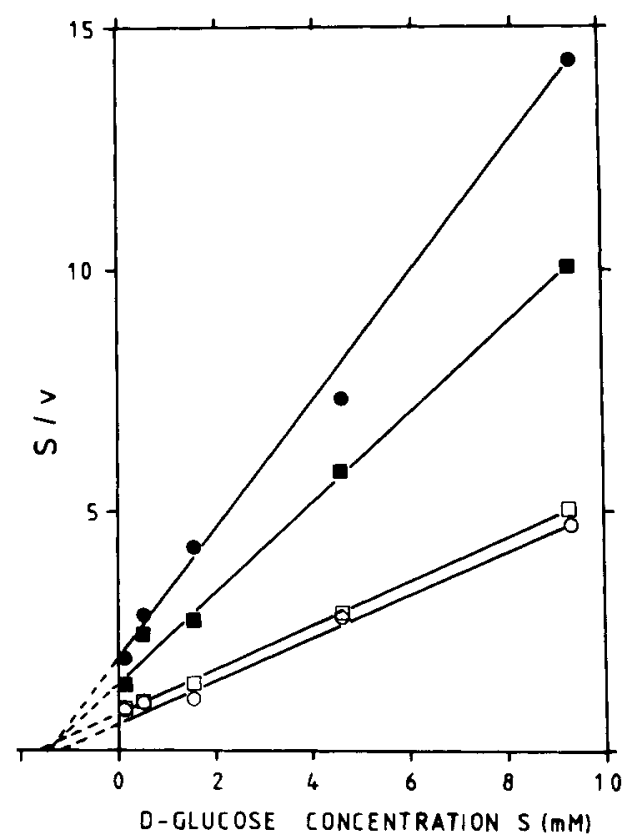

Fig. 3. Plots of $\mathrm{S} / \mathrm{v}$ against $\mathrm{S}(\mathrm{mM}) \mathrm{D}$-glucose concentration in the incubation solution are shown. v: rate of D-glucose uptake in nmoles D-glucose $/ \mu$ l cell space $\times$ min. Open symbols indicate the concentration dependence of the uptake rates of phase II cultures; closed symbols, of late phase III cultures (completed replicative lifespan 100\%). Uptake was measured in all cultures on the same day and under identical conditions. Each point represents the average of triplicate measurements. Round and square symbols represent cell resuspensions from cultures separately processed for uptake measurements.

experiments regression analysis served to estimate the apparent $\mathrm{Km}$ and Vmax of the carrier-mediated D-glucose transport. At the highest D-glucose concentration $(10 \mathrm{mM})$, a slight drop in linearity was occasionally observed. The non-saturable component, however, did never exceed $20 \%$ at $10 \mathrm{mM}$ and was in most cases much smaller. There was no indication of any increase of the non-saturable component during aging in vitro.

The average value and the range of $\mathrm{Km}$ values were the same in phase II and phase III (Table 2, Fig. 4). In contrast to $\mathrm{Km}$, a large variation of transport rates was observed in phase III cultures obtained by different in vitro aging experiments. As an example, Table 1 shows initial transport rates per $\mu \mathrm{l}$ cell space obtained at $0.1 \mathrm{mM}$ D-glucose. Transport rates obtained for phase III cultures were compared with the transport rates for phase II cultures at all D-glucose concentrations tested. This comparison was performed with phase II cultures 
TABLE 2. Apparent Km and Vmax of the D-glucose carrier in phase II and phase III HELF-cultures

\begin{tabular}{|c|c|c|c|c|c|c|c|c|}
\hline \multirow[t]{2}{*}{ Exp. No. } & \multicolumn{2}{|c|}{$\underset{\mathrm{m} \text { moles }}{\mathrm{Km}}$} & \multicolumn{2}{|c|}{$\mathrm{n}$ moles $/ \mu \mathrm{l} \times \min$} & \multicolumn{2}{|c|}{$\begin{array}{c}V \max \\
\mathrm{n} \text { moles } / 10^{6} \text { cells }\end{array}$} & \multicolumn{2}{|c|}{$\begin{array}{l}\mathrm{n} \text { moles } \times 10^{9} / \mu \mathrm{m}^{2} \\
\text { cell surface } \times \mathrm{min}\end{array}$} \\
\hline & phase II & phase III & phase II & phase III & phase II & phase III & phase II & phase III \\
\hline 1 & 1.61 & 1.64 & 2.17 & 1.09 & 5.42 & 7.73 & 6.51 & 4.26 \\
\hline 2 & 1.34 & 1.47 & 2.14 & 0.76 & 6.20 & 3.57 & 6.40 & 2.99 \\
\hline 3 & 1.96 & $*$ & 2.99 & $*$ & 6.88 & $*$ & 8.95 & $*$ \\
\hline 4 & 2.28 & 2.07 & 2.20 & 1.97 & 5.28 & 13.40 & 6.03 & 7.75 \\
\hline 5 & 1.65 & 1.87 & 2.31 & 1.09 & 5.54 & 7.96 & 6.41 & 4.38 \\
\hline $\begin{array}{l}\overline{\mathbf{x}} \\
\text { range }\end{array}$ & $\begin{array}{c}1.77 \\
1.34-2.28\end{array}$ & $\begin{array}{c}1.76 \\
1.47-2.07\end{array}$ & $\begin{array}{c}2.36 \\
2.14-2.99\end{array}$ & $\begin{array}{c}1.23 \\
0.76-1.97\end{array}$ & $\begin{array}{c}5.86 \\
5.28-6.20\end{array}$ & $\begin{array}{c}8.16 \\
3.57-13.4\end{array}$ & $\begin{array}{c}6.86 \\
.03-8.95\end{array}$ & $\begin{array}{c}4.84 \\
2.99-7.75\end{array}$ \\
\hline
\end{tabular}

* Initial transport rates measured in phase III cultures of exp. 3 were too low to allow meaningful calculations of Km and Vmax. $\mathrm{x}$ and range of $\mathrm{Km}$ and Vmax in phase II I is indicated for experiments 1, 2,4 and 5 . Maximum transport rates per mg protein are not included, but can easily be calculated by the ratio given for protein content per $\mu$ l cell water in the text.

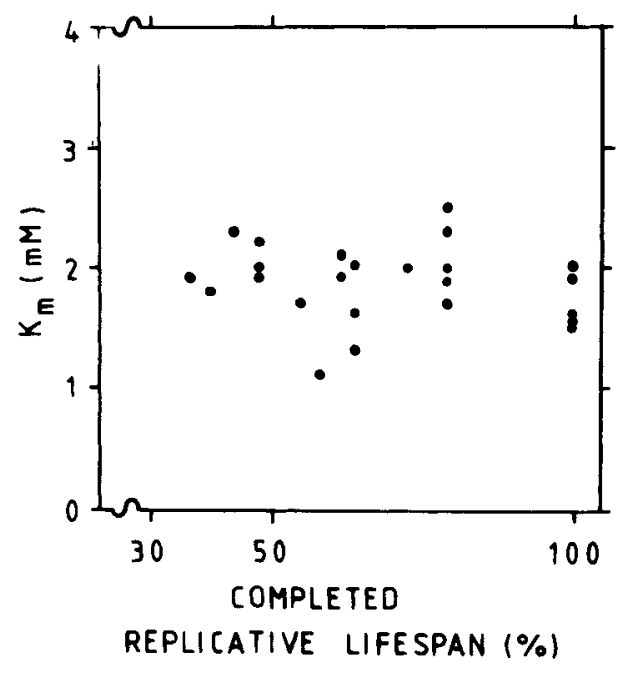

Fig. 4. The apparent $\mathrm{Km}$ of the D-glucose carrier of HELF-strain Flow 2000 is shown as a function of completed replicative lifespan. $\mathrm{Km}$ values obtained for late phase III cultures were in the range of the $\mathrm{Km}$ values obtained for 19 phase II cultures.

included as a control in each of the experiments $1-5$, as well as with a total of 19 phase II cultures, which had completed between $30 \%$ and $80 \%$ of their replicative lifespans (Fig. 5). Transport rates per $\mu$ l cell space were found to be significantly decreased by the paired t-test at all D-glucose concentrations in phase III cultures of experiments $1,2,3$, and $5(\mathrm{p}<0.05$ in all cases, $p<0.01$ in most cases). The same was true when transport rates were expressed per $\mathrm{mg}$ protein in these experiments. These data are not included in Table 1 but can simply be

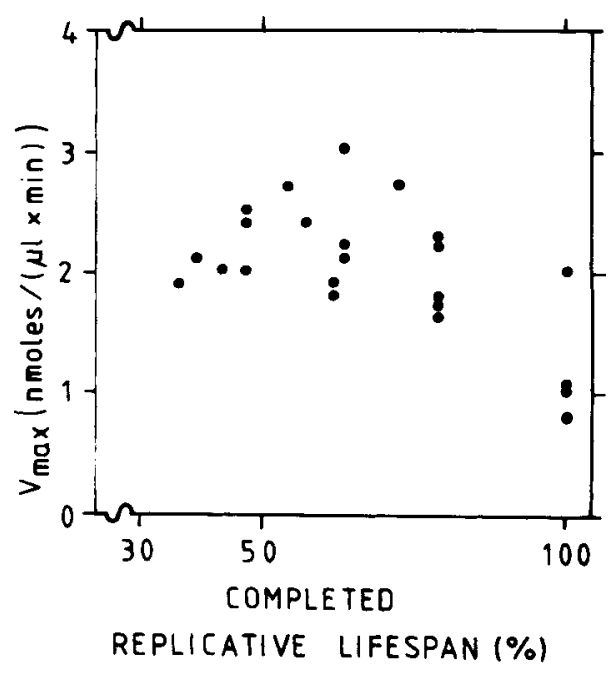

Fig. 5. Maximum transport rates Vmax per $\mu$ l cell space are shown as a function of completed replicative lifespan. A decrease of Vmax was noted in three experiments performed with late phase III cultures. In one experiment, Vmax obtained for late phase III cultures was in the range of 19 phase II cultures, which had completed between $30 \%$ and $80 \%$ of their replicative lifespan. In another experiment, transport rates measured in phase III cultures at D-glucose concentrations between $0.1 \mathrm{mM}$ and $10 \mathrm{mM}$ were too low to determine Vmax by linear regression (compare Table 2).

calculated from the ratio $\mathrm{mg}$ protein $/ \mu \mathrm{l}$ cell space given above. In experiment 3 , transport rates calculated per $10^{6}$ cells were only $25 \%$ or less of the rates of phase II cells within the range of $\mathrm{D}$-glucose concentrations tested (0.1-10 mM), in spite of a nearly threefold increase of senescent cell volume. In experiments 1,2 , and 5, values for Vmax of senescent cul- 
tures ranged between $32 \%$ and $46 \%$ of phase II cultures per unit of cell volume and protein, respectively, between $61 \%$ and $136 \%$ per $10^{6}$ cells, and between $44 \%$ and $64 \%$ per unit of cell surface area $(100 \%$ = average Vmax of phase II cultures in Table 2). In experiment 4, Vmax of the senescent cultures was within the range obtained for phase II cultures when calculated per unit of cell volume, protein, or surface area. Vmax expressed on a cellular basis, however, showed a two- to threefold increase (228\%) over phase II cultures. Figure 5 shows the relationship between Vmax calculated per $\mu$ l cell space and completed replicative lifespan. These measurements were performed throughout the course of 1 year and did not reveal a change of Vmax between $30 \%$ and $80 \%$ completed replicative lifespan. Whatever the reasons for the variation of transport rates in senescent cultures may be, this variation does not appear to be simply a question of length of incubation time after the last subcultivation in different aging experiments in vitro. These times were 1 week in experiment 1,3 weeks in experiment 4 , 6 weeks in experiment 2,8 weeks in experiment 3 , and 10 weeks in experiment 5 . The validity of phase II cultures maintained for prolonged periods of time as controls seemed questionable, since these cultures form tightly packed cell layers. In contrast, senescent cultures were no longer able to reach confluency and were lost after further subcultivation. The only feasible way to maintain these cultures for some time was application of fresh medium at regular intervals. Phase II cultures were routinely used for assay at saturation density 1 week after subcultivation. In this way, transport rates during postreplicative senescence of terminally differentiated cells (Martin et al., '75) were compared with rates of non-growing phase II cells from cultures maintained under the normal subculturing regimen. No decrease of Vmax was observed in assays with phase II cultures grown for 3 weeks, in contrast to phase III cultures of experiment 1 , which showed a decreased Vmax 1 week after a final subcultivation.

\section{DISCUSSION}

The role of plasma membrane in cellular aging is far from clear (Zs.-Nagy, '79). Present data suggest that certain functions of the plasma membrane are altered during cellular senescence, while others are not (Grinna, '77; Kelley et al., '78; Schachtschabel and Wever, '78; Polgar et al., '78; Aizawa and Mitsui, '79). Here we have investigated D-glucose transport during the lifespan in vitro of human embryo lung fibroblasts. D-glucose plays an essential role in the energy metabolism of cultivated cells. Transport as well as the number of glucose binding sites in plasma membrane appear to be altered after malignant transformation (Plagemann, '73; Bramwell and Harris, '78). Since clonal senescence is a characteristic parameter of untransformed cells, it seems important to elucidate the possible significance of glucose transport in this process. We shall consider first the validity of initial rates of D-glucose transport obtained for phase II and phase III cultures, and secondly, possible relationships between alterations of glucose transport and in vitro senescence.

1. The advantages and possible shortcomings of the filtering centrifugation method used for measurements of transport rates have been discussed in detail elsewhere (Werdan et al., '80). Uptake kinetics of suspended cells were measured with trypsin still present in the incubation medium. Our data suggest that the glucose carrier does not expose trypsin-sensitive sites to the cell exterior (Plagemann and Richey, '74). We have shown that trypsin does not alter Vmax and $\mathrm{Km}$ of human embryo lung fibroblasts (Werdan et al., '80). There was no indication of any changes of transport capability of phase II and phase III cells during a period of about half an hour, necessary to measure the concentration dependence of Dglucose uptake.

In the present investigation, initial transport rates of D-glucose were estimated from uptake times as short as $10 \mathrm{sec}$. We have reason to assume that this time was short enough to obtain valid estimates, probably still somewhat too low for initial transport rates. Let us consider some quantitative aspects concerning the possible influence of backflow and metabolism of ${ }^{14} \mathrm{C}$-glucose on the estimated rates. Since Dglucose is rapidly phosphorylated and the cell membrane is nearly impermeable for phosphorylated hexoses, one cannot refer to the total intracellular activity when considering the problem of backflow. An estimate of backflow can be performed as follows. After $20 \mathrm{sec}$ of incubation with $1 \mathrm{mM}$ D-glucose, intracellular radioactivity had attained $25 \%$ equilibrium. About $50 \%$ of this activity consisted of free ${ }^{14} \mathrm{C}$ glucose, the rest of phosphorylated compounds (Werdan et al., '80). Furthermore, uptake was linear during the first $20 \mathrm{sec}$ and mainly carrier-mediated both in phase II and phase III cultures. Assuming that $\mathrm{Km}$ and Vmax of the carrier for D-glucose are identical in both di- 
rections of the cell membrane, one can calculate that backflow within this time range was smaller than $10 \%$. At $0.1 \mathrm{mM}$ D-glucose the relative transport velocity v/S was about $50 \%$ higher than at $1.0 \mathrm{mM}$, and backflow increased accordingly but did not exceed $15 \%$ of uptake during the first $20 \mathrm{sec}$. At higher glucose concentrations the error due to backflow became even smaller than at $1 \mathrm{mM}$.

Loss of radioactivity due to the production of ${ }^{14} \mathrm{CO}_{2}$ and ${ }^{14} \mathrm{C}$-lactate seems to be of minor importance, since D-glucose uptake measured after 20 sec remained unaltered when the glycolytic pathway was blocked by the inhibition of glyceraldehyde-3-phosphate dehydrogenase by iodoacetic acid (Werdan et al., '80). The effect of metabolism on D-glucose uptake was only investigated with phase II cells because of the limited amount of cell material available in phase III. Available data, however, do not suggest an underestimation of the rates in senescent cells due to a more rapid $\mathrm{CO}_{2}$ and lactate formation. There is no indication that the cellular aging process is accompanied by changes in the glycolytic capacity of WI-38 fibroblasts (Cristofalo and Kritchevsky, '66). Using a cell strain derived from skin of a normal 22-year-old male, Goldstein and Trieman (75) have shown that late passage fibroblasts consume 1.5-3 times more glucose per cell than early passage cells. This difference correlated with the increase of cell volume and protein content in late passage cells and was abolished when the data were expressed per unit of volume or protein.

When comparing present data for D-glucose transport and utilization, the different genetic origin of cell strains used by Cristofalo and Kirtchevsky ('66), Goldstein and Trieman ('75), and our group is a potential problem. Furthermore, their studies on glucose utilization were performed with late passage cultures, which were still one to several population doublings before the end of the replicative lifespan, while in the present experiments senescent cultures had completely exhaused their replicative lifespans. However, if any changes of glucose metabolism in senescent Flow 2000 fibroblasts would have profoundly affected measurements of transport rates during the first $20 \mathrm{sec}$ of incubation, we should have observed a detectable deviation from linearity.

The choice of a "best" denominator to express transport rates deserves special consideration. The supply of cells of different size with glucose may be best compared by expressing data per unit of volume or protein, while a comparison of transport rates per unit area of cell surface is necessary in order to discuss differences of membrane function. Reliable estimates of cell surface area are difficult to obtain. Our estimation was based on the assumption that cells in suspension are smooth spheres. This may not necessarily be valid, especially in late passage cells, which frequently have odd shapes. Furthermore, the cell surface is not smooth, and differences in the surface topography of young and senescent cells were not taken into consideration (Bowman and Daniel, '75; Blomquist et al., '77). In spite of these deficiencies, the surface estimates should be sufficient for the present purpose. The assumption of spheres tends to minimize the increase of cell surface with increasing cell volume. Therefore, transport rates per unit area of senescent cells when compared to rates in phase II cells may be overestimated rather than underestimated. We conclude that estimates of D-glucose transport that we have presented for the different denominators discussed above are valid both for phase II and phase III cultures.

2. A number of authors favor the idea that proteins are altered in aging cells (for review, see Martin, '77; Rothstein, '77; McKerrow, '79). Although senescent cultures were maintained in the postreplicative state for prolonged periods of time in order to observe the maximum effect, we did not find any change of the affinity of the carrier for D-glucose. In contrast to $\mathrm{Km}$, a large variation of transport rates was observed in senescent cultures. Several reasons for this variation may be considered. Due to the wide variation in the proliferative potential of clones and subclones, senescent mass cultures are composed of cells from few clones which outlive the other (Smith and Hayflick, '74; Harley and Goldstein, '78; Smith and Whitney, '80). Thus, variation of glucose transport in senescent mass cultures may reflect variation of transport in different aging clones. The length of time for which postreplicative senescent cells were maintained may be a critical parameter. A comparison of these times in different aging experiments is not feasible, merely on account of time periods for which phase III cultures were maintained after their last subcultivation. Furthermore, some differences in handling of senescent cultures may have escaped our notice and profoundly affected transport rates, although much care was taken to standardize culture conditions.

Recently, Germinario et al. ('80) have reported an investigation of 2-deoxy-D-glucose transport in human skin fibroblast cultures 
that had completed between $20 \%$ and $90 \%$ of the life span in vitro. Their results confirm our previous observation that the $\mathrm{Km}$ of the glucose carrier does not change during aging in vitro (Cremer et al., '79). The maximum transport capacity per cell for 2-DG transport increased almost twofold with increasing age in vitro. No increase, however, was found when the results were expressed per mg protein. Taking into account the correlation between an increase of protein content and cell volume in aging fibroblast cultures (Haslam and Goldstein '74; Schneider and Shorr, '75; this paper), this increase may merely reflect the larger surface area of older cells as compared with younger cells and does not necessarily indicate any change in the transport capability of plasma membrane per se during aging in vitro. In our study only a slight increase of cell size was noted between $30 \%$ and $80 \%$ of the replicative lifespan, while Vmax per $\mu$ l cell space and $\mu \mathrm{m}^{2}$ surface area remained fairly constant. After having completely exhausted their replicative lifespan, some senescent cultures had still maintained glucose transport rates of phase II cells when expressed per unit of cell volume, protein, and surface area, respectively, but showed a more than twofold increase of Vmax per $10^{6}$ cells.

Other senescent cultures were no longer able to compensate for the increase in cell size and showed only slightly increased or even strongly decreased transport rates per $10^{6}$ cells. Present data (Cristofalo and Kritchevsky, '66; Goldstein and Trieman, '75; Germinario et al., '80; this paper) argue against the idea that an impairment of D-glucose transport and glucose metabolism might precede the loss of replicative potential observed in phase III cultures. Instead our data point to a correlation between a decrease of D-glucose transport during postreplicative senescence in terminally differentiated cells (Martin et al., '75) and degeneration of these cells. This suggestion is supported by the finding that no D-glucose uptake was observed into the inulin-impermeable space of degenerating cells flushed off from senescent cultures, while cell suspensions prepared from firmly attached cells of the same cultures still showed considerable transport rates. A remarkable increase of the space freely accessible to inulin and glucose was noted in "degenerating cell fractions," suggesting gross permeability defects in some of the degenerating cells.

Impairment of D-glucose transport in terminally differentiated cells may indicate a gen- eral phenomenon including other substances as well. Polgar et al. ('78) have investigated uridine transport in young and old human embryo lung fibroblasts and did not detect any differences in $\mathrm{Km}$. In late passage cultures, in which only $5 \%$ of the cells could be stimulated to divide with fresh culture medium, a 1.5-fold increase of Vmax per cell as compared with early passage cells was found. Since the average cell volume of late passage cells was 3.5fold increased $\left(6.4 \mu \mathrm{l} / 10^{6}\right.$ old cells versus 1.8 $\mu \mathrm{l} / 10^{6}$ young cells), this means a considerable decrease of Vmax when expressed per unit of cell volume and surface area, respectively. While it is tempting to suggest that a normal $\mathrm{Km}$ combined with a decrease of Vmax per unit of surface area reflects decreased numbers of carriers in senescent cell membrane, alterations of carriers itself or other changes in cell membranes during aging, which may indirectly influence the transport capacity of carriers, should also be taken into consideration.

\section{LITERATURE CITED}

Aizawa, S., and Y. Mitsui (1979) A new cell surface marker of aging in human diploid fibroblasts. J. Cell Physiol., 100:383-388.

Berumen, L., and A. Maciera-Coelho (1977) Changes in albumin uptake during the lifespan of human fibroblasts in vitro. Mech. Age Dev., 6:165-172.

Blomquist, E., U. Brunk, B. Westermark, and A. Arro (1977) Surface characteristics of phase II and III cells in culture. In: Scanning electron microscopy. O. Johari, ed., IIT Research Institute, Chicago, pp. 13-20.

Bowman, P.D., and C.D. Daniel (1975) Aging of human fibroblasts in vitro: Surface features and behavior of aging WI-38 cells. Mech. Age Dev., 4:147-158.

Bramwell, M.E., and H. Harris (1978) Some further information about the abnormal membrane glycoprotein associated with malignancy. Proc. R. Soc. Lond. B., 203:93-99.

Cremer, T., K. Werdan, and A.F.G. Stevenson (1979) Aging in vitro and D-glucose uptake kinetics of diploid human fibroblasts (abstract). Hoppe-Seyler's Z. Physiol. Chem., 360:246.

Cristofalo, V.F., and B.B. Sharf (1973) Cellular senescence and DNA svnthesis. Exp. Cell Res., 76:419-427.

Cristofalo, V.J., and D. Kritchevsky (1966) Respiration and glycolysis in the human diploid cell strain WI-38. J. Cell Physiol., 67:125-132.

Germinario, R.J., M. Oliveira, and M. Taylor (1980) Studies of the effects of in vitro ageing on saturable and nonsaturable sugar uptake in cultured human skin fibroblasts. Gerontology, 26:181-187.

Goldstein, S., and G. Trieman (1975) Glucose consumption by early and late-passage diploid human fibroblasts during growth and stationary phase. Experientia, 31/2:177180.

Grinna, L.S. (1977) Changes in cell membranes during aging. Gerontology, 23:452-464.

Harley, B.C., and S. Goldstein (1978) Cultured human fibroblasts: distribution of cell generations and a critical limit. J. Cell. Physiol, 97:509-516.

Haslam, R.J., and S. Goldstein (1974) Adenosine 3' :5' -cyclic monophosphate in young and senescent human fibroblasts 
during growth and stationary phase in vitro. Effects of prostaglandin $\mathrm{E} 1$ and of adrenaline. Biochem. J., 144:253-263.

Hayflick, L., and P.S. Moorhead (1961) The serial cultivation of human diploid cell strains. Exp. Cell Res., 25:585-621.

Hayflick, L. (1965) The limited in vitro lifetime of human diploid cell strains. Exp. Cell Res., 37:614-636.

Heldt, H.W. (1980) Measurement of metabolite movement across the envelope and of the $\mathrm{pH}$ in the stroma and the thylakoid space in intact chloroplasts. In: Methods in enzymology; S.P. Colowick and N.O. Kaplan, eds. Vol. 69 (A San Pietro, ed.). Academic Press, New York, pp. 604-613.

Hirschberg, C.B. (1977) Phospholipid turnover in hamster and chick embryo fibroblasts. Exp. Cell Res., 110:355-361.

Kaplan, J., and M. Moskowitz (1975) Studies on the turnover of plasma membrane in cultured mammalian cells I. Rates of synthesis and degradation of plasma membrane proteins and carbohydrates. Biochem. Biophys. Acta, 389:290-305.

Kelley, O.R., R. Azad, and K.G. Vogel (1978) Development of the aging cell surface: concanavalin A-mediated intercellular binding and the distribution of binding sites with progressive subcultivation of human embryo lung fibroblasts. Mech. Age Deve., 8:203-217.

Klingenberg, M., and E. Pfaff (1967) Means of terminating reactions. In: methods in Enzymology, S.P. Colowick and N.O. Kaplan, eds., Vol. 10 (R.W. Estabrook and M.E. Pullman, eds.). Academic Press, New York, pp. 680-684.

Lowry, O.H., N.J. Rosebrough, A.L. Farr, and R.J. Randal (1951) Protein measurement with the Folin phenol reagent. J. Biol. Chem., 193:265-275.

Martin, G.M., C.A. Sprague, T.H. Norwood, W.R. Pendergrass, P. Bornstein, H. Hoehn, and W.P. Arend (1975) Do hyperplastoid cell lines "differentiate themselves to death"? Adv. Exp. Med. Biol., 53:67-90.

Martin, G.M. (1977) Cellular aging-clonal senescencepostreplicative cells. Am. J. Pathol., 89:484-530.

McKerrow, J.H. (1979) Non-enzymatic, posttranslational, amino acid modifications in aging. A brief review. Mech. Age Dev., 10:371-377.

Plagemann, P.G.W. (1973) Deoxyglucose transport by uninfected, murine sarcoma virus-transformed, and murine leukemia virus-infected mouse cells. J. Cell. Physiol., 82:421-434.

Plagemann, P.G.W., and D.P. Richey (1974) Transport of nucleosides, nucleic acid bases, choline and glucose by animal cells in culture. Biochim. Biophys. Acta, 344:263305.

Polgar, P., L. Taylor, and L. Brown (1978) Plasma mem- brane associated metabolic parameters and the aging of human diploid fibroblasts. Mech. Age Dev., 7:151-160.

Roberts, R.M., and B. O-C. Yuan (1975) Turnover of plasma membrane polypeptides in nonproliferating cultures of Chinese hamster ovary cells and human skin fibroblasts. Arch. Biochem. Biophys., 171:234-244.

Rothstein, M. (1977) Recent developments in the age-related alteration of enzymes: a review. Mech. Age Dev., 6:241257.

Schachtschabel, D.O., and J. Wever (1978) Age-related decline in the synthesis of glycosaminoglycans by cultured human fibroblasts (WI-38). Mech. Age Dev., 8:257-264.

Schneider, E.L., and E.J. Stanbridge (1975) A simple biochemical technique for the detection of mycoplasma contamination of cultured cells. In: Methods in Cell Biology, D.M. Prescott, ed. Academic Press, New York, Vol X, pp. 277-290.

Schneider, E.L., and B.J. Fokles (1976) Measurement of DNA content and cell volume in senescent human fibroblasts utilizing flow multipe rameter single cell analysis. Exp. Cell Res., 98:298-302.

Schneider, E.L., and S.S. Shorr (1975) Alteration in cellular RNAs during the in vitro lifespan of cultured human fibroblasts. Cell, 6:179-184.

Simons, J.W.I.M. (1967) The use of frequency distributions of cell diameters to characterize cell populations in tissue culture. Exp. Cell Res., 45:336-350.

Smith, J.R., and L. Hayflick (1974) Variation in the life-span of clones derived from human diploid cell strains. J. Cell Biol., 62:48-53.

Smith, J.R., and R.G. Whitney (1980) Intraclonal variation in proliferative potential of human diploid fibroblasts: stochastic mechanism for cellular aging. Science, 207:82 84 .

Stevenson, A.F.G., T. Cremer, and O. Messerschmidt (1977) Erholung und zytogerontologische Aspekte der menschlichen Bindegewebszellen nach Röntgen- und Neutronenbestrahlung. In: Strahlenschutz in Forschung und Praxis, Band XVIII, O. Messerschmidt et al., eds., Georg Thieme Verlag, Stuttgart, pp. 20-29.

Werdan, K., K. Lehner, T. Cremer, A.F.G. Stevenson, and O. Messerschmidt (1980) D-glucose transport in suspended human fibroblasts. Rapid measurement of uptake by silicone oil filtration centrifugation and comparison of different cell detachment procedures. Hoppe Seyler's Z. Physiol. Chem., 361:91-104.

Zs.-Nagy, I. (1979) The role of membrane structure and function in cellular aging: a review. Mech. Age Dev., 9:237246 . 